\title{
Application of MOORA method for multi optimization of GMAW process parameters in stain- less steel cladding
}

\author{
Suha K. Shihab ${ }^{a}$, Noor Zaman Khan ${ }^{b^{*}}$, Pratyush Mylac, Sanjay Upadhyay ${ }^{d}$, Zahid A. Khan ${ }^{b}$ \\ and Arshad Noor Siddiquee ${ }^{b}$
}

${ }^{a}$ Department of Materials Engineering, College of Engineering, University of Diyala, Diyala, Iraq

${ }^{b}$ Department of Mechanical Engineering, Jamia Millia Islamia (A Central University), New Delhi-110025, India

${ }^{c}$ Lead Engineer - Piping and Arrangement in the Department of HRSG Engineering, Gas Power Systems, GE Power India Limited, Noida, India

${ }^{d}$ Workshop Instructor, YMCA University of Science and Technology, Faridabad, India

\section{CH R O N I C L E}

Article history:

Received: November 26, 2017

Received in revised format: No-

vember 26, 2017

Accepted: February 7, 2018

Available online:

February 7, 2018

Keywords:

MOORA

Cladding

GMAW

Optimization

\section{A B S T R A C T}

Gas Metal Arc Welding (GMAW) is widely used to perform cladding so as to enhance corrosion resistance and several other properties of substrate material. However, the success of cladding using GMAW depends on the optimal selection of its critical parameters. Therefore, in this study, the cladding of stainless steel over mild steel substrate using GMAW process is investigated with an aim to optimize the GMAW process parameters. Three GMAW process parameters i.e. current, voltage, and torch angle were selected and their effect on the time required to complete the cladding and arc power was investigated and optimized. Multiple objective optimization based on ratio analysis (MOORA) method was employed to evaluate and optimize the effect of the selected process parameters. It was found that the current and voltage have significant effect in reducing the time and power required for the cladding process.

\section{Introduction}

Metal cladding is a process used to protect base material via deposition of a thin layer of second material on the surface of the base material. This process plays a significant role as it provides corrosion protection, wear protection to the base material and at the same time it is also cost effective (Akramifard et al., 2014; Dhib et al., 2016; Cao et al., 2015). There are different cladding processes which are essentially used to reduce the cost and improve the properties of engineering components. GMAW is one of the processes which is highly suitable for cladding because of its high efficiency, reliability, high deposition rate, low cost, user-friendliness, suitability for both nonferrous and ferrous metals (Zhang et al., 2014; Scotti et al., 2014). The cladding of stainless steel includes depositing a layer of stainless steel over the mild steel substrate through GMAW process. The cladding of stainless steel provides

* Corresponding author. Tel.:+91-011-26985176

E-mail address: noor0315@yahoo.com (N.Z. Khan) 
resistance to the oxidation, abrasion and corrosion of the mild steel. In addition, the cladding of stainless material also contributes to increase in the strength of substrate and improves the thermal conductivity of the composite (Luo et al., 2016). Further, cladding of stainless steel is also expected to offer economic advantages. However, cladding is considered to be a complicated welding process due to involvement of many input process parameters and multiple response variables. Thus, it is necessary to control as accurately as possible the cladding process parameters to obtain the desired quality of the deposited material (Palani \& Murugan, 2007). Statistical design of experiment methods has been used to study different welding processes by several researchers for determining the effect of process parameters and they verified that these methods can be efficiently employed to obtain the desired results with reasonable accuracy (Bidi et al., 2017; Balasubramanian, 2016; Martinez-Conesa et al., 2017). Therefore, in this study, Taguchi $\mathrm{L}_{27}$ orthogonal array was used to perform the experiments to investigate the effect of different GMAW process parameters i.e. voltage, current, torch angle on two response variables i.e. time required to complete the bead and the arc power.

MOORA method (multiple objective optimization based on ratio analysis) is a well-known multi-criterion or multi attribute optimization method which can be employed to solve various types of complex decision-making problems in the manufacturing environment (Shihab \& Chanda, 2015; Patel \& Maniya, 2015; Gadakh et al., 2013). In addition, it is an easy method which can be used to determine the optimum values of a process involving multi responses. Therefore, in this study, MOORA method is used in order to determine the optimum parameters during cladding process.

\section{Materials and methods}

The substrate material was mild steel (IS 2062) plates with dimensions of $300 \times 200 \times 20 \mathrm{~mm}$. The surfaces of substrate material were ground before cladding to remove dirt and to smooth finish. A filler wire of stainless steel - Grade 308L was used. The chemical composition of the filler wire and substrate material is presented in Table 1. GMAW machine (make: ESAB AUTO K400, India) was used for cladding. Current (A), Voltage (B), torch angle (C) were selected as input process parameters. Table 2 reveals the levels of process parameters that were used in the present study. Argon was used as shielding gas as it is relatively cleaner than other gases and its flow was kept constant i.e. $10 \mathrm{l} / \mathrm{min}$. Time (T) required to complete the bead was recorded with the help of a stop watch and its unit is second. Power was obtained by multiplying voltage and current whose values were displayed by the GMAW machine. Its unit is Watt (W). Fig.1 illustrates the typical cladded plates.

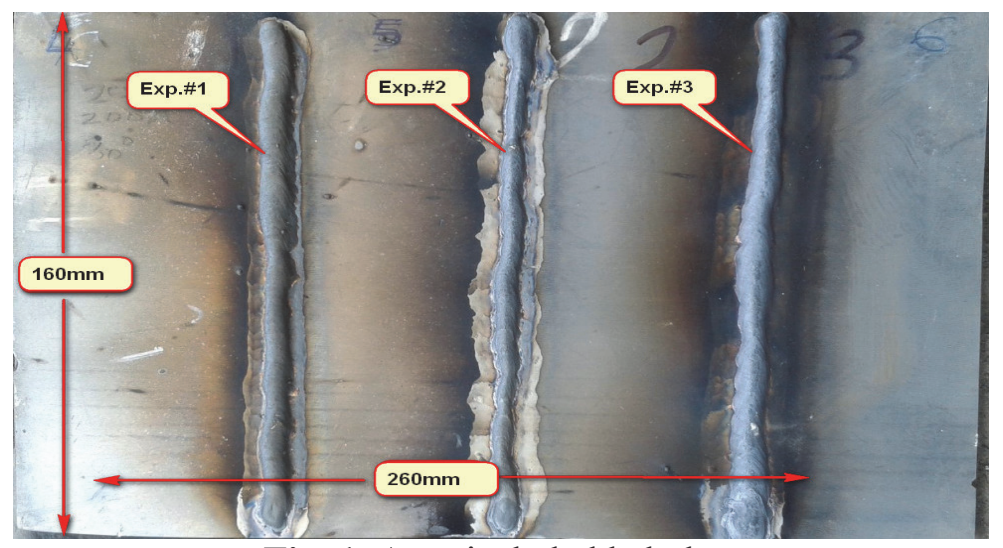

Fig. 1. A typical cladded plate

\section{Table 1}

Chemical composition of based Metal and Filler wire in \% weights

\begin{tabular}{lllllllllll}
\hline Elements & C & Si & Mn & S & P & Cr & Mo & Ni & Cu & Fe \\
\hline IS 2062 & 0.161 & 0.091 & 0.910 & 0.008 & 0.015 & 0.017 & 0.002 & 0.008 & 0.018 & Rest \\
W30813 & 0.04 & 1 & 1.32 & 0.03 & 0.04 & 19.9 & 0.75 & 9.5 & 0.75 & Rest \\
\hline
\end{tabular}


Table 2

Levels of input welding parameters levels

\begin{tabular}{cccccc}
\hline Factors & Process Variable & Units & \multicolumn{2}{c}{ Levels } \\
\hline A & Current & A & 20 & 25 & 30 \\
B & Voltage & V & 200 & 230 & 260 \\
C & Torch Angle & $\circ$ & 30 & 45 & 60 \\
\hline
\end{tabular}

\subsection{SDV-MOORA Method}

Selecting and evaluating multiple responses of the manufacturing processes is Multi-Criteria Decision Making (MCDM) problem. The importance of weights in solving Multi-Criteria Decision Making (MCDM) problems cannot be over emphasized. The standard deviation (SDV) method suits the problem of allocating weights in MCDM. MOORA method is a multi-objective optimization on the basis of ratio analysis that can be efficiently used to solve various kinds of complex decision problems of manufacturing environment (Gadakh et al., 2013, Brauers et al., 2008). Therefore, in this study, SDV was used to allocate weights to the two response variables. The approach thus used in the present study is called SDV-MOORA which can be applied when no preference among the criteria is considered. Lower-the-better criterion was used for both the response variables i.e. time required to complete the bead and the arc power. The normalization of the response variables was done using Eq. (1) in order to convert different units among different criteria into measurable units to facilitate weights calculation (Achebo \& Odinikuku, 2015).

$$
X^{\prime}{ }_{i j}=\frac{X_{i j}-\min _{1<j<n} X_{i j}}{\max _{1<j<n} X_{i j}-\min _{1<j<n} X_{i j}},
$$

where, min and max are the maximum and minimum values of the criterion $(j)$ respectively. The standard deviation (SDV) is computed for every criterion using Eq. (2) (Achebo \& Odinikuku, 2015)

$$
\mathrm{SDV}_{\mathrm{j}}^{\prime}=\sqrt{\frac{1}{\mathrm{~m}} \sum_{\mathrm{i}=1}^{\mathrm{m}}\left(\mathrm{X}^{\prime}-\overline{\mathrm{X}^{\prime}}{ }_{\mathrm{j}}\right)^{2}},
$$

where ${\overline{X^{\prime}}}_{j}$ is the mean of the values of the $j$ th criterion after normalization and $j=1,2, \ldots ., \mathrm{n}$. After calculating the SDV for all criterions, the weights $\left(\mathrm{W}_{\mathrm{j}}\right)$ were calculated by Eq. (3) (Achebo \& Odinikuku, 2015).

$$
\mathrm{W}_{\mathrm{j}}=\frac{\mathrm{SDV}_{\mathrm{j}}^{\prime}}{\sum_{\mathrm{j}=1}^{\mathrm{n}} \mathrm{SDV}_{\mathrm{j}}^{\prime}}
$$

The decision matrix being used in the MOORA method can be obtained by Eq. (4) (Chakraborty, 2010).

$$
X=\left[\begin{array}{ccccccc}
X & X_{12} & \cdots & \cdots & \cdots & \cdots & X_{1 n} \\
X_{11} & X_{22} & \cdots & \cdots & \cdots & \cdots & X_{2 n} \\
\cdots & \cdots & \cdots & \cdots & \cdots & \cdots & \cdots \\
\cdots & \cdots & \cdots & \cdots & \cdots & \cdots & \cdots \\
X_{m 1} & X_{m 2} & \cdots & \cdots & \cdots & \cdots & X_{m n}
\end{array}\right]
$$

where $m$ represents the number of alternatives, $n$ indicates number of attributes., and $X i j$ is the representation measure of $i$ th alternative on $j$ th attribute, The normalized decision matrix is calculated by Eq. (5) (Chakraborty, 2010) 


$$
\mathrm{X}^{\prime}{ }_{\mathrm{ij}}=\frac{\mathrm{X}_{\mathrm{ij}}}{\sqrt{\sum_{\mathrm{i}=1}^{\mathrm{m}} \mathrm{X}_{\mathrm{ij}}^{2}}}
$$

Then optimization problem can be defined by Eq. (6):

$$
\mathrm{y}_{\mathrm{i}}=\sum_{\mathrm{j}=1}^{\mathrm{b}} \mathrm{X}_{\mathrm{ij}}^{\prime}-\sum_{\mathrm{j}=\mathrm{b}+1}^{\mathrm{n}} \mathrm{X}_{\mathrm{ij}}^{\prime}
$$

$\sum_{j=1}^{b} X^{\prime}{ }_{i j}$ and $\sum_{j=b+1}^{n} X_{i j}^{\prime}$ are the interest and non-interest criteria respectively. If there are different attributes more significant than the others, the combined score is obtained using $\mathrm{W}_{\mathrm{j}} \mathrm{where}$ $\mathrm{W}_{\mathrm{j}}$ is the weight of $j$ th criterion. Ranking of $y i$ in descending order gives the final priority.

\section{Results and discussions}

Taguchi's orthogonal array of $\mathrm{L}_{27}$ was used as a design of experiment. The design of experiment with the results of Time required to complete the bead $(\mathrm{T})$ and the $\operatorname{arc}$ power $(\mathrm{P})$ are tabulated in Table 3 .

Table 3

DOE Matrix with experimental results of time and arc power

\begin{tabular}{llllllllllll}
\hline Exp. Run & $\mathbf{A}$ & $\mathbf{B}$ & $\mathbf{C}$ & $\mathbf{T}(\mathbf{s e c})$ & $\mathbf{P}(\mathbf{W})$ & $\mathbf{E x p}$. Run & $\mathbf{A}$ & $\mathbf{B}$ & $\mathbf{C}$ & $\mathbf{T}(\mathbf{s e c})$ & $\mathbf{P}(\mathbf{W})$ \\
\hline $\mathbf{1}$ & 20 & 200 & 30 & 26 & 4000 & $\mathbf{1 5}$ & 30 & 230 & 30 & 23 & 6900 \\
$\mathbf{2}$ & 25 & 200 & 45 & 16 & 5000 & $\mathbf{1 6}$ & 20 & 260 & 45 & 18 & 5200 \\
$\mathbf{3}$ & 30 & 200 & 60 & 20 & 6000 & $\mathbf{1 7}$ & 25 & 260 & 60 & 24 & 6500 \\
$\mathbf{4}$ & 20 & 230 & 30 & 24 & 4600 & $\mathbf{1 8}$ & 30 & 260 & 30 & 19 & 7800 \\
$\mathbf{5}$ & 25 & 230 & 45 & 16 & 5750 & $\mathbf{1 9}$ & 20 & 200 & 60 & 20 & 4000 \\
$\mathbf{6}$ & 30 & 230 & 60 & 21 & 6900 & $\mathbf{2 0}$ & 25 & 200 & 30 & 25 & 5000 \\
$\mathbf{7}$ & 20 & 260 & 30 & 20 & 5200 & $\mathbf{2 1}$ & 30 & 200 & 45 & 25 & 6000 \\
$\mathbf{8}$ & 25 & 260 & 45 & 23 & 6500 & $\mathbf{2 2}$ & 20 & 230 & 60 & 25 & 4600 \\
$\mathbf{9}$ & 30 & 260 & 60 & 22 & 7800 & $\mathbf{2 3}$ & 25 & 230 & 30 & 16 & 5750 \\
$\mathbf{1 0}$ & 20 & 200 & 45 & 23 & 4000 & $\mathbf{2 4}$ & 30 & 230 & 45 & 13 & 6900 \\
$\mathbf{1 1}$ & 25 & 200 & 60 & 16 & 5000 & $\mathbf{2 5}$ & 20 & 260 & 60 & 15 & 5200 \\
$\mathbf{1 2}$ & 30 & 200 & 30 & 22 & 6000 & $\mathbf{2 6}$ & 25 & 260 & 30 & 24 & 6500 \\
$\mathbf{1 3}$ & 20 & 230 & 45 & 22 & 4600 & $\mathbf{2 7}$ & 30 & 260 & 45 & 23 & 7800 \\
$\mathbf{1 4}$ & 25 & 230 & 60 & 15 & 5750 & & & & & &
\end{tabular}

Table 4 shows the value of standard deviation that has been calculated using Eq. (2). In addition, the weights were calculated using Eq. (3) and the results are tabulated in Table 5.

Table 2

Summary of standardized decision matrix

\begin{tabular}{lcccccccc}
\hline Exp. Run \# & Time & Power & Exp. Run \# & Time & Power & Exp. Run \# & Time & Power \\
\hline $\mathbf{1}$ & 1 & 0 & $\mathbf{1 0}$ & 0.769231 & 0 & $\mathbf{1 9}$ & 0.538462 & 0 \\
$\mathbf{2}$ & 0.230769 & 0.263158 & $\mathbf{1 1}$ & 0.230769 & 0.263158 & $\mathbf{2 0}$ & 0.923077 & 0.263158 \\
$\mathbf{3}$ & 0.538462 & 0.526316 & $\mathbf{1 2}$ & 0.692308 & 0.526316 & $\mathbf{2 1}$ & 0.923077 & 0.526316 \\
$\mathbf{4}$ & 0.846154 & 0.157895 & $\mathbf{1 3}$ & 0.692308 & 0.157895 & $\mathbf{2 2}$ & 0.923077 & 0.157895 \\
$\mathbf{5}$ & 0.230769 & 0.460526 & $\mathbf{1 4}$ & 0.153846 & 0.460526 & $\mathbf{2 3}$ & 0.230769 & 0.460526 \\
$\mathbf{6}$ & 0.615385 & 0.763158 & $\mathbf{1 5}$ & 0.769231 & 0.763158 & $\mathbf{2 4}$ & 0 & 0.763158 \\
$\mathbf{7}$ & 0.538462 & 0.315789 & $\mathbf{1 6}$ & 0.384615 & 0.315789 & $\mathbf{2 5}$ & 0.153846 & 0.315789 \\
$\mathbf{8}$ & 0.769231 & 0.657895 & $\mathbf{1 7}$ & 0.846154 & 0.657895 & $\mathbf{2 6}$ & 0.846154 & 0.657895 \\
$\mathbf{9}$ & 0.692308 & 1 & $\mathbf{1 8}$ & 0.461538 & 1 & $\mathbf{2 7}$ & 0.769231 & 1 \\
\hline
\end{tabular}

\section{Table 5}

Weights assigned to criteria

\begin{tabular}{ccc}
\hline Property & $\boldsymbol{S D \boldsymbol { V } _ { \boldsymbol { j } } ^ { \prime }}$ & $\boldsymbol{W}_{\boldsymbol{j}}$ \\
\hline Time & 0.2888 & 0.217208 \\
Power & 0.301816 & 0.226987 \\
\hline
\end{tabular}


Then, MOORA method was applied on the obtained data using Eq. (4) and Eq. (5), respectively to obtain the normalized decision matrix as shown in Table 6.

Table 6

Normalized decision matrix

\begin{tabular}{|c|c|c|c|c|c|}
\hline Exp. Run & Time & Power & Exp. Run & Time & Power \\
\hline 1 & 0.239187 & 0.131385 & 15 & 0.211589 & 0.226639 \\
\hline 2 & 0.147192 & 0.164232 & 16 & 0.165591 & 0.170801 \\
\hline 3 & 0.18399 & 0.197078 & 17 & 0.220788 & 0.213501 \\
\hline 4 & 0.220788 & 0.151093 & 18 & 0.174791 & 0.256201 \\
\hline 5 & 0.147192 & 0.188866 & 19 & 0.18399 & 0.131385 \\
\hline 6 & 0.19319 & 0.226639 & 20 & 0.229988 & 0.164232 \\
\hline 7 & 0.18399 & 0.170801 & 21 & 0.229988 & 0.197078 \\
\hline 8 & 0.211589 & 0.213501 & 22 & 0.229988 & 0.151093 \\
\hline 9 & 0.202389 & 0.256201 & 23 & 0.147192 & 0.188866 \\
\hline 10 & 0.211589 & 0.131385 & 24 & 0.119594 & 0.226639 \\
\hline 11 & 0.147192 & 0.164232 & 25 & 0.137993 & 0.170801 \\
\hline 12 & 0.202389 & 0.197078 & 26 & 0.220788 & 0.213501 \\
\hline 13 & 0.202389 & 0.151093 & 27 & 0.211589 & 0.256201 \\
\hline 14 & 0.137993 & 0.188866 & Weight, $W_{j}$ & 0.217208 & 0.226987 \\
\hline
\end{tabular}

Table 7

Results of multi objective analysis

\begin{tabular}{|c|c|c|c|c|c|c|c|c|c|}
\hline $\begin{array}{l}\text { Exp. } \\
\text { Run }\end{array}$ & T (Sec.) & Power & $\sum \max -\sum \min$ & Rank & $\begin{array}{l}\text { Exp. } \\
\text { Run }\end{array}$ & T (Sec.) & Power & $\sum m$ & Rank \\
\hline 1 & 0.051953 & 0.029823 & 0.081776 & 15 & 15 & 0.045959 & 0.051444 & 0.097403 & 3 \\
\hline 2 & 0.031971 & 0.037278 & 0.06925 & 26 & 16 & 0.035968 & 0.03877 & 0.074737 & 22 \\
\hline 3 & 0.039964 & 0.044734 & 0.084698 & 12 & 17 & 0.047957 & 0.048462 & 0.096419 & 5 \\
\hline 4 & 0.047957 & 0.034296 & 0.082253 & 14 & 18 & 0.037966 & 0.058154 & 0.09612 & 6 \\
\hline 5 & 0.031971 & 0.04287 & 0.074842 & 20 & 19 & 0.039964 & 0.029823 & 0.069787 & 24 \\
\hline 6 & 0.041962 & 0.051444 & 0.093407 & 9 & 20 & 0.049955 & 0.037278 & 0.087234 & 11 \\
\hline 7 & 0.039964 & 0.03877 & 0.078734 & 16 & 21 & 0.049955 & 0.044734 & 0.094689 & 7 \\
\hline 8 & 0.045959 & 0.048462 & 0.094421 & 8 & 22 & 0.049955 & 0.034296 & 0.084251 & 13 \\
\hline 9 & 0.043961 & 0.058154 & 0.102115 & 2 & 23 & 0.031971 & 0.04287 & 0.074842 & 21 \\
\hline 10 & 0.045959 & 0.029823 & 0.075782 & 19 & 24 & 0.025977 & 0.051444 & 0.077421 & 18 \\
\hline 11 & 0.031971 & 0.037278 & 0.06925 & 25 & 25 & 0.029973 & 0.03877 & 0.068743 & 27 \\
\hline 12 & 0.043961 & 0.044734 & 0.088695 & 10 & 26 & 0.047957 & 0.048462 & 0.096419 & 4 \\
\hline 13 & 0.043961 & 0.034296 & 0.078257 & 17 & 27 & 0.045959 & 0.058154 & 0.104113 & 1 best \\
\hline 14 & 0.029973 & 0.04287 & 0.072843 & 23 & & & & & \\
\hline
\end{tabular}

The $y_{i}$ values were obtained using Eq. (6) and based on its value ranks were decided as shown in Table 7. It can be observed from Table 7 that the rank of experiment number 27 is 1 . Thus, the optimum combination of parameters is $\mathrm{A}_{3} \mathrm{~B}_{3} \mathrm{C}_{2}$ i.e current $30 \mathrm{~A}$, voltage $260 \mathrm{~V}$ and torch angle $45^{\circ}$. Thus, it can be concluded that the higher values of the current and voltage have the most significant effect on the time required to complete the bead and the arc power. Voltage is an electromotive force which is highly responsible for the impingement of metal droplet to the substrate. Higher voltage leads to reduction in time and the power required for the welding. Torch angle is only responsible for impingement direction and does not have any electrical interaction during weld cladding.

\section{Conclusions}

The effect of GMAW process parameters (current, voltage and torch angle) on the time to complete the bead and the arc power during cladding stainless steel on mild steel was studied. A statistical design (Taguchi $\mathrm{L}_{27}$ ) was used as an experimental technique to conduct the experimental work. The MOORA method was used to choose the multi optimum welding process parameters that generate lower time and power required. Further, standard deviation (SDV) method was employed to allocate the weights to the response variables. It has been noticed that the MOORA method has effectively optimized the GMAW parameters considered in the present study. From the obtained results of this study, following conclusions are made:

- The optimum combination of GMAW process parameters used for cladding is $\mathrm{A}_{3} \mathrm{~B}_{3} \mathrm{C}_{2}$ i.e. the current $30 \mathrm{~A}$, voltage $260 \mathrm{~V}$ and the torch angle $45^{\circ}$. 
- Maximum value of current, within the selected range of the levels, reduces the time and power required for the cladding process.

- Maximum value of voltage, within the selected range of the levels, reduces the time and power required for the cladding process.

- Value of torch angle, within the selected range of the levels, has no significant effect on the time and power required for the cladding process.

\section{References}

Achebo, J., \& Odinikuku, W. (2015). Optimization of Gas Metal Arc Welding Process Parameters Using Standard Deviation (SDV) and Multi-Objective Optimization on the Basis of Ratio Analysis (MOORA). Journal of Minerals and Materials Characterization and Engineering, 03(04), 298-308.

Akramifard, H., Mirzadeh, H., \& Parsa, M. (2014). Cladding of aluminum on AISI 304L stainless steel by cold roll bonding: Mechanism, microstructure, and mechanical properties. Materials Science and Engineering: A, 613, 232-239.

Balasubramanian, M. (2016). Prediction of optimum weld pool geometry of PCTIG welded titanium alloy using statistical design. Engineering Science and Technology, An International Journal, 19(1), 15-21.

Bidi, L., Le Masson, P., Cicala, E., \& Primault, C. (2017). Experimental design method to the weld bead geometry optimization for hybrid laser-MAG welding in a narrow chamfer configuration. Optics \& Laser Technology, 89, 114-125.

Brauers, W., Zavadskas, E., Peldschus, F., \& Turskis, Z. (2008). Multi-objective optimization of road design alternatives with an application of the MOORA method. Transport, 23(3), 183-193.

Cao, X., Ding, X., Lu, Y., Zhu, P., \& Shoji, T. (2015). Influences of Cr content and PWHT on microstructure and oxidation behavior of stainless steel weld overlay cladding materials in high temperature water. Journal of Nuclear Materials, 467, 32-41.

Chakraborty, S. (2010). Applications of the MOORA method for decision making in manufacturing environment. The International Journal of Advanced Manufacturing Technology, 54(9-12), 1155-1166.

Dhib, Z., Guermazi, N., Gaspérini, M., \& Haddar, N. (2016). Cladding of low-carbon steel to austenitic stainless steel by hot-roll bonding: Microstructure and mechanical properties before and after welding. Materials Science and Engineering: A, 656, 130-141.

Gadakh, V., Shinde, V., \& Khemnar, N. (2013). Optimization of welding process parameters using MOORA method. The International Journal of Advanced Manufacturing Technology, 69(9-12), 2031-2039.

Luo, K., Jing, X., Sheng, J., Sun, G., Yan, Z., \& Lu, J. (2016). Characterization and analyses on micro-hardness, residual stress and microstructure in laser cladding coating of 316L stainless steel subjected to massive LSP treatment. Journal of Alloys And Compounds, 673, 158-169.

Martinez-Conesa, E., Egea, J., Miguel, V., Toledo, C., \& Meseguer-Valdenebro, J. (2017). Optimization of geometric parameters in a welded joint through response surface methodology. Construction and Building Materials, 154, 105-114.

Palani, P., \& Murugan, N. (2007). Optimization of weld bead geometry for stainless steel claddings deposited by FCAW. Journal of Materials Processing Technology, 190(1-3), 291-299.

Patel, J., \& Maniya, K. (2015). Application of AHP/MOORA Method to Select Wire Cut Electrical Discharge Machining Process Parameter to Cut EN31 Alloys Steel with Brasswire. Materials Today: Proceedings, 2(45), 2496-2503.

Scotti, A., Ponomarev, V., \& Lucas, W. (2014). Interchangeable metal transfer phenomenon in GMA welding: Features, mechanisms, classification. Journal of Materials Processing Technology, 214(11), 2488-2496.

Shihab, S., \& Chanda, A. (2015). Multi response optimization of milling process parameters using moora method. International Journal of Mechanical and Production Engineering, 3(4), 67-71.

Zhang, H., Chang, Q., Liu, J., Lu, H., Wu, H., \& Feng, J. (2014). A novel rotating wire GMAW process to change fusion zone shape and microstructure of mild steel. Materials Letters, 123, 101-103.

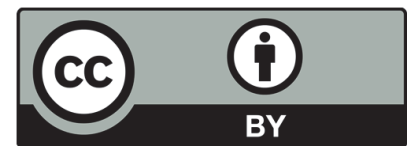

(C) 2018 by the authors; licensee Growing Science, Canada. This is an open access article distributed under the terms and conditions of the Creative Commons Attribution (CC-BY) license (http://creativecommons.org/licenses/by/4.0/). 